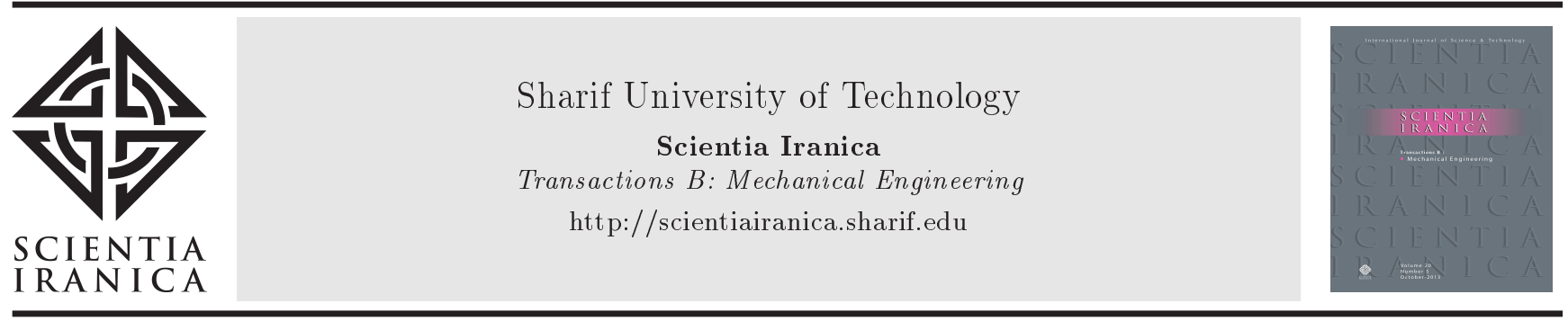

\title{
A generalized finite element approach to the free vibration analysis of non-uniform axially functionally graded beam
}

\author{
R.P. Sahu, M.K. Sutar*, and S. Pattnaik \\ Department of Mechanical Engineering, VSSUT Burla, Burla-768018, Sambalpur, Odisha, India.
}

Received 3 December 2020; received in revised form 9 May 2021; accepted 19 July 2021

\section{KEYWORDS \\ Generalized finite element; \\ Free vibration; \\ AFG beam; \\ Power law; \\ Exponential law; \\ Fundamental \\ frequency.}

\begin{abstract}
The present study aims to present a generalized finite element approach to the free vibration analysis of an Axially Functionally Graded (AFG) beam characterized by non-uniform thickness. Application of the non-uniform beam element and assembling make the finite element model a generalized one. The current approach can be applied to beams with both uniform and non-uniform thicknesses and any of the homogenous and inhomogeneous material variations. The governing equation for free vibration of beam was derived from Euler-Bernoulli beam theory as well as Euler-Lagrange equation. As observed throughout the study, the cross-section of the beam decreased along the length depending on the exponential function related to variations in thickness. Material inhomogeneity is determined according to the power and exponential law of material variation along the axial direction, taken from the literature. Mathematical modeling of the geometric nonuniformity, material inhomogeneity, and finite element analysis of the AFG beam was achieved using MATLAB software. The effects of geometric non-uniformity and material gradient parameters on the fundamental frequencies of vibration in different classical boundary conditions were also evaluated. A comparison of the results of available literature can guarantee the efficacy of the proposed method.
\end{abstract}

(C) 2022 Sharif University of Technology. All rights reserved.

\section{Introduction}

As inevitable parts of any mechanical structure, beams have numerous applications ranging from micro-beams used in MEMS devices to those used in large structures like aircraft carriers. Recent advances in manufacturing composite materials have made it possible to replace conventional beam materials with the composite ones

*. Corresponding author. Tel.: +918763270195

E-mail address: mihirsutar05@gmail.com (M.K. Sutar)

doi: $10.24200 /$ sci.2021.57274.5151 owing to their high strength-to-weight ratio. Functionally Graded Materials (FGMs) are one of the outcomes of such scientific advances in the field of composite materials. The idea of FGM first came into picture in the mid 80's to solve the problem of a space plane project in Japan, where the capability of material to remain resistant against the external temperature of $2100 \mathrm{~K}$ and a gradient of $1600 \mathrm{~K}$ was needed for a very small thickness [1]. Since then, FGMs have gained widespread popularity as thermal barrier materials in a wide range of engineering applications such as nuclear reactors, defense systems, automobiles, aerospace, spacecraft, etc. 
In this regard, FGMs can be defined as a relatively new class of composite materials with a continuous variation of composition and/or microstructure in a particular direction; however, unlike conventional laminated composites, they possess no specific material interface, hence less stress concentrations in them [2]. Such variations in composition called grading can be made for any of the material properties such as porosity, density, elasticity, thermal or electrical conductivity, etc. Given their wide scope, the present study is limited to mechanical properties such as density and elasticity, which directly affect the mechanical behaviors such as bending, buckling, and vibration of the beams or any other mechanical element of a structure for that matter.

Given the type of extreme dynamic conditions present in a wide range of FGM applications like aerospace and defense, having a better understanding of the dynamics of any mechanical system made of FGM gains significance. To this end, to understand the dynamics better, especially from the design perspective, a great deal of attention has been drawn to the study of natural frequencies. For instance, Kapuria et al. [3] studied the free vibration responses of functionally graded beams of a layered type with two different combinations of aluminum/silicon carbide and nickel/alumina at the theoretical level using experimental validation. The response prediction was performed using the zig-zag theory in conjunction with the modified rule of mixtures. Yang and Chen [4] investigated free vibration and buckling behavior of functionally graded beams with open edge cracks through an analytical approach based on the rotational-spring model. Alshorbagy et al. [5] evaluated the effect of different material distributions on the thickness direction of a beam of uniform thickness using Finite Element Method (FEM). Their numerical results revealed that the material variation parameter in the longitudinal direction certainly affected the natural frequency and mode shape of the beam. Simsek and Kocaturk [6] analyzed the free and forced vibration characteristics as well as the dynamic behavior of a functionally graded simply supported beam under a concentrated moving harmonic load. They considered functional grading along the thickness direction using the power law and law of exponents and concluded that different material distributions, velocity of the moving harmonic load, and excitation frequency played a considerable role in determining the dynamic behavior of the FG beam. Pradhan and Chakraverty [7] explored the vibration characteristics of Euler-Bernoulli FGM beams using the integral approach of Rayleigh-Ritz method. They concluded that the frequency parameters in the downhill manner with both end fixed supports being the highest followed by one end fixed and one simply supported and both the end simply supported FGM beams follow the same pattern as that of isotropic beams independent of the complexity in material variations. Rao and Ganesan [8] parametrically evaluated the effects of taper profile and taper parameter on the harmonic response of a beam tapered in several manners. They concluded that different types of taper provided in the beam caused inter laminar stress development on the free edges. Karami et al. [9] employed Differential Quadrature Element Method (DQEM) based on the theory of shear deformable beams to analyze the free vibration of beams with non-uniform thickness. They proved that the differential quadrature technique for beams which were neither uniform nor continuous in thickness profile was proved to be an accurate tool owing to its viable applicability. Aydogdu and Taskin [10] analyzed the free vibration response of a simply supported FGM beam made of material gradient in the thickness direction and followed the law of exponents, unlike most of the other studies mentioned above. They established a system of motion equations based on Hamilton's principle and offered Navier type solution. In this study, Higher-order Shear Deformation Theory (HSDT) and Classical Beam Theory (CBT) were used for analysis. They concluded that CBT could yield better results than HSDT, and the difference between the results of two theories increased upon increasing the mode number. Nguyen and Quoc [11] used a new shear deformation theory to analyze the free vibration of functionally graded rectangular plates through the finite element approach. They evaluated the effects of material gradation and geometric parameters on the natural vibration frequencies of the functionally graded plate using the Hamiltonian approach to finding the governing equations of motion.

Apparently, despite the great deal effort made in this field, a majority of these studies are still confined to the analysis of beams with uniform thickness and grading along the thickness direction. Recently, a number of researchers have analyzed FGM in the axial direction. Huang and $\mathrm{Li}$ [12] considered a new approach to solve the free vibration of AFG Euler-Bernoulli beams of non-uniform cross-section and focused on Fredholm's integral approach rather than solving a relatively complex differential equation consisting of variable coefficients with the fourth order. Cao et al. [13] suggested an approximate analytical solution methodology for power-law-based AFG beam using Euler-Bernoulli beam theory as well as Asymptotic Development Method (ADM). Ghayesh [14] assessed the state of non-linearity in the vibration of tapered AFG beam using Third-order Shear Deformation Theory (TSDT). Huang et al. [15] studied the whirling frequency and critical speed of a spinning AFG beam and modeled it according to Timoshenko Beam Theory (TBT). They used spectral Chebyshev method for the derivation of governing differential equation as well 
as solution and found that the axial grading had a profound impact on the whirling frequency and critical speed, specifically under cantilever boundary conditions. A new computationally efficient modification of the well-known method of Initial Parameters in Differential Form (IPDF) was proposed by Salinic et al. [16]. The proposed method called the Symbolic Numeric Method of Initial Parameters (SNMIP) was used for the vibration analysis of the tapered and segmented types of Euler-Bernoulli AFG beam. Zheng et al. [17] opted for a Modified Couple Stress Theory (MCST) and Euler-Bernoulli beam theory, considering the geometric nonlinearity of von Karman type for nonlinear finite element modeling of the axially graded tapered micro beam undergoing nonlinear vibration. Sahin et al. [18] selected TBT and completed the finite element modeling based on Hamilton principle for the free vibration investigation of double tapered Axially Functionally Graded Beam (AFGB). Xie et al. [19] carried out a dynamic analysis of AFG beam considering both CBT and TBT. The governing equation of motion was derived using Lagrange's theorem; therefore, the longitudinal and transverse coupling effect of vibration can be recognized. The numerical technique of Newmark as well as the direct iteration method were used for obtaining the solution. In the analysis of transverse and longitudinal beam vibrations under combined axial loads, Sun and Li [20] relied on TBT, considered it as an initial value problem, and employed the fourth-order Runge-Kutta method for solution.

Isogeometric Analysis (IGA) of FGMs is a leap in the numerical analysis process. It acts like a connection between the FGM model and Finite Element Analysis (FEA). Several attempts have been reported in this domain in the literature. Hughes et al. [21] introduced the idea of IGA. Nguyen et al. [22] proposed a novel quasi-3D shear deformation theory in association with IGA. The proposed approach was successfully used in the cases of rectangular and circular functionally graded micro-plates for static bending, free vibration, and buckling analysis. Thanh et al. [23] proposed a refined MCST based on IGA and Hamilton's principle to analyze laminated composite micro-plates. Three material-length scale parameters were considered instead of one using asymmetric couple stress curvature tensor. The approach was found more accurate. Thanh et al. [24] analyzed the behavior of porous micro plates in thermal and post buckling using MCST along with IGA under different boundary conditions. Thanh et al. [25] used IGA and MCST in carbon nanotube reinforced composite nanoplates. Van et al. [26] proposed a shear deformation theory in association with IGA for nonlinear transient analysis of piezoelectric FGM plates. The proposed methodology was found to be effective compared to the standard ones. Van et al. [27] also used IGA for the analysis of porous FG nanoplates. They observed that the nonlinear response in the form of deflection was affected by porosity, material properties, etc. In addition, IGA and MCST were considered in the analysis of composite laminate microplates [28] to study the buckling behavior under thermal loading conditions. As observed, upon increasing the material length scale ratio, the values of such parameters as thermal central deflection, shear and axial stresses, and critical temperature decreased. Nguyen et al. [29] analyzed a thin walled functionally graded beam with a non-uniform polygonal cross-section. They considered HSDT in their analysis to model the complex geometry and used ABAQUS platform for the FEA. Finding a computationally efficient process even after considering the practical aspects of distortion warping, they brought light to a new pathway for research in the area of shell-like structure analysis. Until now, a majority of the mentioned studies have focused on the unidirectional variation of properties; however, Nguyen and Lee considered the variation of the bi-directional material properties for the flexural-torsional vibration analysis of thin-walled beams. They found that the location of the center of gravity and shear center were imperatively sensitive to the type of variation in geometry as well as material distribution [30,31].

In this regard, the current study aims to present a simplified finite element approach to the free vibration of non-uniform AFG beam. The analysis of nonuniform beams faced a difficulty, i.e., the definition beam element which itself changes every time and causes a major problem while assembling the elements. Hence, the problems of different kinds of nonuniformity as well as material gradation schemes were acknowledged, and results were conformed to those of the existing literature.

\section{Mathematical modelling of FGB}

\subsection{Geometry of the FGB}

In the present analysis of free transverse vibration, a beam with length $L$, width $b$, and thickness $g(x)$ was taken into account, as shown in Figure 1. Here, $g(x)$ is regarded as an exponential function of the axial location ' $x$ ' with respect to the original at $O$ making

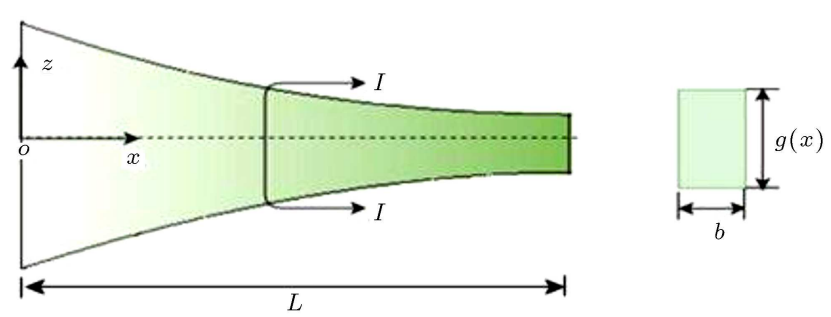

Figure 1. The non-uniform geometry of the beam with variable thickness $g(x)$. 
the thickness and the cross-section variable along the axial direction of the beam.

In the problem, $x z$-plane is referred to as the plane of vibration. Therefore, $g(x)$ can be obtained as:

$$
g(x)=h_{0} e^{-\beta \frac{x}{L}}
$$

\subsection{Material gradation}

The material properties of the beam such as Young's Modulus $E(x)$ and mass density $\rho(x)$ vary axially based on the exponential law of gradation used by Cao et al. [13] as well as the power law of material gradation proposed by Rajasekaran and Khaniki [32]. The effective material property $P(x)$ at a certain distance $x$ from the origin along the axial direction is determined by the rule of mixture [33], as shown in the following:

$$
\begin{aligned}
& P(x)=P_{L} V_{L}+P_{R} V_{R}, \\
& \text { For } \quad V_{L}+V_{R}=1,
\end{aligned}
$$

where $V_{L}$ is the volume fraction of the material used in the left most interface of the beam, i.e., at $x=0$, and $V_{R}$ the volume fraction of the material used in the right most part of the beam, i.e., at $x=L . P_{L}$ and $P_{R}$ present the material properties of the left and right most surfaces of the beam.

$$
P(x)=P_{L}+\left(P_{R}-P_{L}\right) V_{R} .
$$

For exponential law of grading [13], we have:

$$
\begin{array}{ll}
V_{R}=\frac{e^{\alpha \frac{x}{L}}-1}{e^{\alpha}-1} \quad \text { when } \quad \alpha \neq 0, \\
V_{R}=\left(\frac{x}{L}\right) & \text { when } \quad \alpha=0 .
\end{array}
$$

For power law of grading [32], we have:

$$
V_{R}=\left(\frac{x}{L}\right)^{n} \quad \text { where } \quad n>0 .
$$

A graphical representation of the variation in the material properties along the beam length is given for different values of the gradient parameters ' $\alpha$ ' for exponential law and ' $n$ ' for the power law of grading in Figures 2 and 3, respectively. For the exponential law of variation, with an increase in ' $\alpha$ ', the richness of the property of the right end material would decrease. The same happens with an increase in the power law exponent ' $n$ '.

\section{The Finite Element Formulation (FEA)}

\subsection{Beam element description}

In order to carry out the FEA, a two-node non-uniform beam element with two degrees of freedom at node, i.e., displacement along the $z$-direction and rotation in the $x z$-plane, was used, as shown in Figure 4 . In this figure, while $W_{1}$ and $W_{2}$ are the transverse displacements of Nodes 1 and $2, \theta_{1}$ and $\theta_{2}$ are the rotations at Nodes 1 and 2 , respectively.

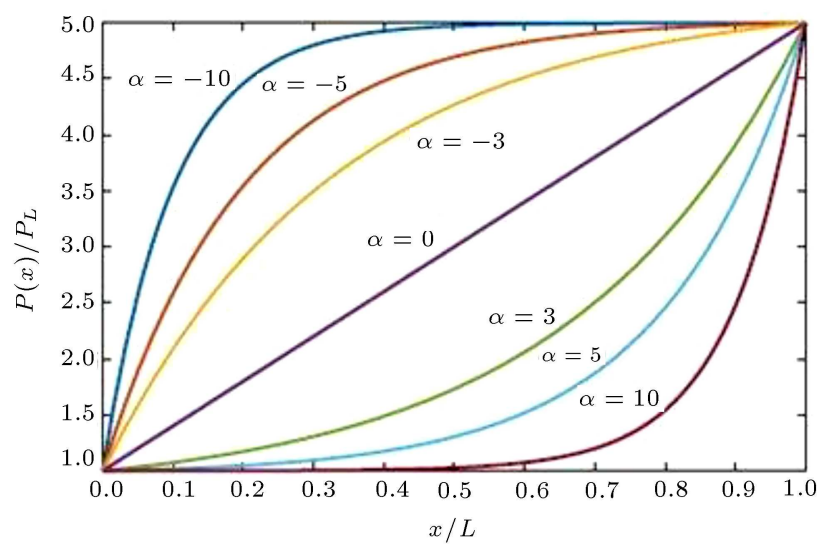

Figure 2. Exponential property variation with respect to beam length for $P_{R}=5 P_{L}$.

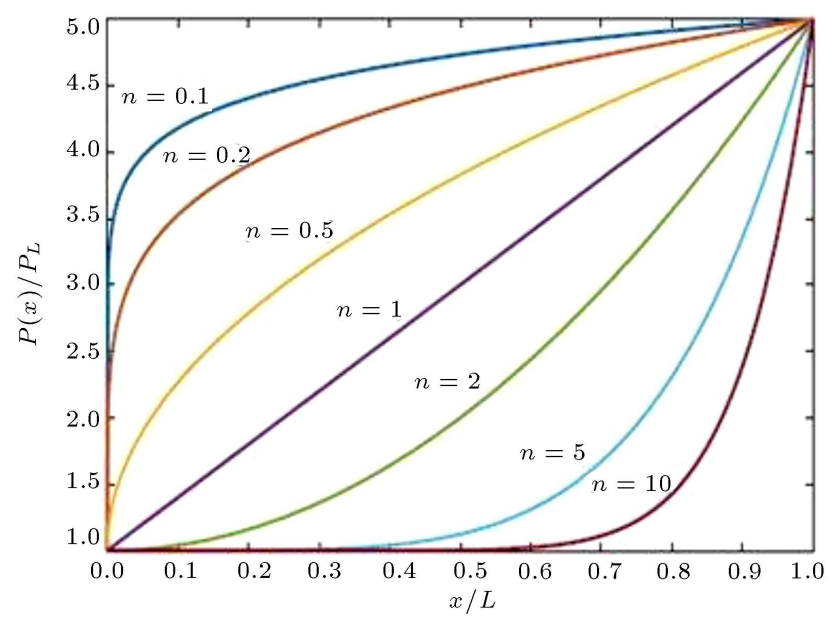

Figure 3. Property variation based on power law with respect to beam length for $P_{R}=5 P_{L}$.

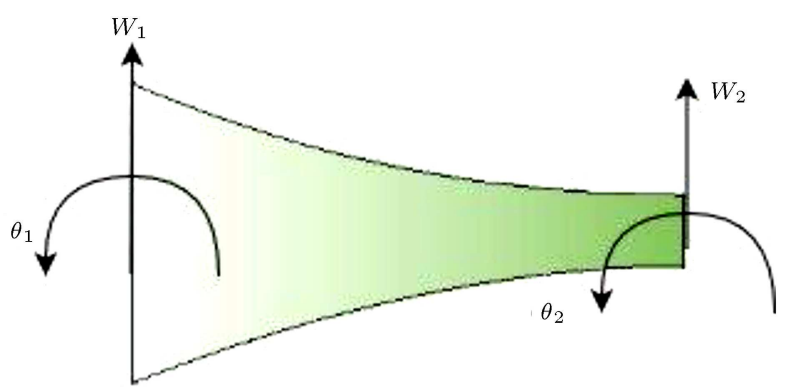

Figure 4. A two-node non-uniform beam element.

3.2. Derivation of governing dynamic equation In this problem, the transverse displacement, $W$, can be formulized as follows:

$$
w=[N(\zeta)]\{d\}
$$

where $[N(\zeta)]$ is the shape function vector that depends only on the local co-ordinate $\zeta$, and $\{d\}$ is the vector containing the nodal variables that is dependent only on time. For a beam element, the local co-ordinate $\zeta$ is defined as follows: 


$$
\zeta=\frac{x-l_{i}}{l_{i+1}-l_{i}}=\frac{x-l_{i}}{s},
$$

where $x$ is the axial co-ordinate in the global coordinate system and $l_{i}$ the axial distance of the $i$ th node from the origin. Now, $s$ is constant for the same element spans which depends upon the number of elements measured through the analysis. Hence, the value of $\zeta$ varies from 0 to 1 for a given element.

According to the Euler-Bernoulli beam theory, the bending moment $M$ is related to the transverse displacement $W(x, t)$ of the beam, as observed in the following:

$$
M=E(x) I(x) \frac{\partial^{2} w}{\partial x^{2}},
$$

where $E(x)$ is Young's modulus and $I(x)$ the area moment of inertia of the beam cross located at a distance $x$ from the origin $O$. Considering the local co-ordinate, Eq. (10) can be written as follows:

$$
M=E(\zeta) I(\zeta) \frac{1}{s^{2}}\left(\frac{\partial^{2} w}{\partial \zeta^{2}}\right) .
$$

Strain energy ' $U$ ' of beam element can be obtained in the following:

$$
U=\int_{0}^{L} \frac{M^{2}}{2 E(x) I(x)} d x .
$$

Now, using the value of $M$ from Eq. (10), we can obtain the strain energy:

$$
U=\int_{0}^{L} \frac{1}{2} E(x) I(x)\left(\frac{\partial^{2} w}{\partial x^{2}}\right)^{2} d x .
$$

Considering $\zeta$, strain energy can be expressed as follows:

$$
U=\frac{1}{2 s^{3}} \int_{0}^{1} E(\zeta) I(\zeta)\left(\frac{\partial^{2} w}{\partial \zeta^{2}}\right)^{2} d \zeta .
$$

Now, we have $[N(\zeta)]=\left[\begin{array}{llll}N_{1} & N_{2} & N_{3} & N_{4}\end{array}\right]$ and $\{d\}=$ $\left[\begin{array}{llll}w_{1} & \theta_{1} & w_{2} & \rho_{2}\end{array}\right]^{T}$. Here, $N_{i}$ is called the shape function, and these values are defined based on Hermite polynomials, as shown in the following:

$$
\begin{array}{ll}
N_{1}=1-3 \zeta^{2}+2 \zeta^{3}, & N_{2}=s\left(\zeta-2 \zeta^{2}+\zeta^{3}\right), \\
N_{3}=3 \zeta^{2}-2 \zeta^{3}, & N_{4}=s\left(\zeta^{3}-\zeta^{2}\right) .
\end{array}
$$

Then, we have:

$$
\frac{\partial^{2} w}{\partial \zeta^{2}}=\left[\begin{array}{llll}
\frac{\partial^{2} N_{1}}{\partial \zeta^{2}} & \frac{\partial^{2} N_{2}}{\partial \zeta^{2}} & \frac{\partial^{2} N_{3}}{\partial \zeta^{2}} & \frac{\partial^{2} N_{4}}{\partial \zeta^{2}}
\end{array}\right]\{d\}=[N, \zeta \zeta]\{d\},
$$

and:

$$
\left(\frac{\partial^{2} w}{\partial \zeta^{2}}\right)^{2}=\{d\}^{T}\left[N,{ }_{\zeta \zeta}\right]^{T}[N, \zeta \zeta]\{d\} .
$$

Therefore, Eq. (14) is written as follows:

$$
U=\frac{1}{2 s^{3}}\{d\}^{T} \int_{0}^{1} E(\zeta) I(\zeta)[N, \zeta \zeta]^{T}[N, \zeta \zeta] d \zeta\{d\} .
$$

The strain energy of the beam element is expressed as follows:

$$
U=\frac{1}{2}\{d\}^{T}[k]\{d\},
$$

where $[k]$ is the element stiffness matrix defined as:

$$
[k]=\frac{1}{s^{3}} \int_{0}^{1} E(\zeta) I(\zeta)\left[N_{{ }_{\zeta \zeta}}\right]^{T}[N, \zeta \zeta] d \zeta .
$$

In a similar manner, the consistent element mass matrix $[m]$ of the beam is obtained. The kinetic energy $T$ of the beam can be calculated as:

$$
T=\frac{1}{2} \int_{0}^{L} \rho(x) A(x) \dot{w}^{2} d x
$$

Now:

$$
\dot{w}=[N(\zeta)]\{\dot{d}\},
$$

and:

$$
\dot{w}^{2}=\{\dot{d}\}^{T}[N]^{T}[N]\{\dot{d}\} .
$$

The kinetic energy of the beam element is defined as follows:

$$
T=\frac{1}{2}\{\dot{d}\}^{T}[m]\{\dot{d}\} .
$$

Hence:

$$
[m]=s \int_{0}^{1} \rho(\zeta) A(\zeta)[N]^{T}[N] d \zeta .
$$

Given that both strain energy and kinetic energy of the beam element are known, the Euler-Lagrange equation of motion [6] of the form is used in the following:

$$
\frac{\partial L_{g}}{\partial\{d\}}-\frac{d}{d t}\left(\frac{\partial L_{g}}{\partial\{\dot{d}\}}\right)=0
$$

where the Lagrangian functional $L_{g}$ is defined as:

$$
-L_{g}=T-V \text {. }
$$

Now, by substituting Eqs. (19), (23), and (26) into Eq. (25), the transverse motion of the beam element can be obtained: 


$$
[m]\{\ddot{d}\}+[k]\{d\}=0 .
$$

Given that $\{d\}$ is a function of time only, it can be expressed as follows:

$$
\{d\}=\left\{\begin{array}{c}
w_{1} \\
\theta_{1} \\
w_{2} \\
\theta_{2}
\end{array}\right\}=\left\{\begin{array}{l}
d_{1} \\
d_{2} \\
d_{3} \\
d_{4}
\end{array}\right\} e^{i \omega t}=\{D\} e^{i \omega t}
$$

where $\omega$ is the fundamental frequency of the beam element undergoing transverse vibration. Now, by substituting $\{d\}$ into Eq. (27), an eigenvalue problem can be obtained:

$$
\left[[k]-\omega^{2}[m]\right]\{D\} e^{i \omega t}=0 .
$$

\subsection{Assembly of elements}

Eq. (29) is used for a single element; however, the number of elements in the FEA should increase to obtain more accurate results; yet, all other factors are considered fixed. Hence, the need for an increase in the number of elements is inevitable. However, given that each of these elements is different in terms of geometry and material properties, another problem arises which is assembling the elements.

In order to solve the problem, before assembling, it is of significance to measure the stiffness and mass matrix of each element by solving Eqs. (20) and (24), respectively, unlike the assembly of homogeneous uniform beam elements.

For a single element problem, the material properties are:

$$
\begin{aligned}
& E(x)=E_{L}+\left(E_{R}-E_{L}\right) V_{R}, \\
& \rho(x)=\rho_{L}+\left(\rho_{R}-\rho_{L}\right) V_{R},
\end{aligned}
$$

where the value of $V_{R}$ can be calculated using Eqs. (5), (6), and (7). The geometric properties are given below:

$$
\begin{aligned}
& A(x)=b \cdot g(x), \\
& I(x)=\frac{b\{g(x)\}^{3}}{12},
\end{aligned}
$$

where the value of ' $g(x)$ ' is measured using Eq. (1). Here, as the number of elements increased, the global co-ordinate ' $x$ ' in each of the above four equations should be replaced by the expression given below and then, the element stiffness and mass matrices can be determined for the assembly.

$$
x=l_{i}+s \zeta,
$$

where all the symbols have the same meaning that has been defined earlier. Given the tedious calculations, integration, etc., MATLAB coding platform was used to solve the problem.

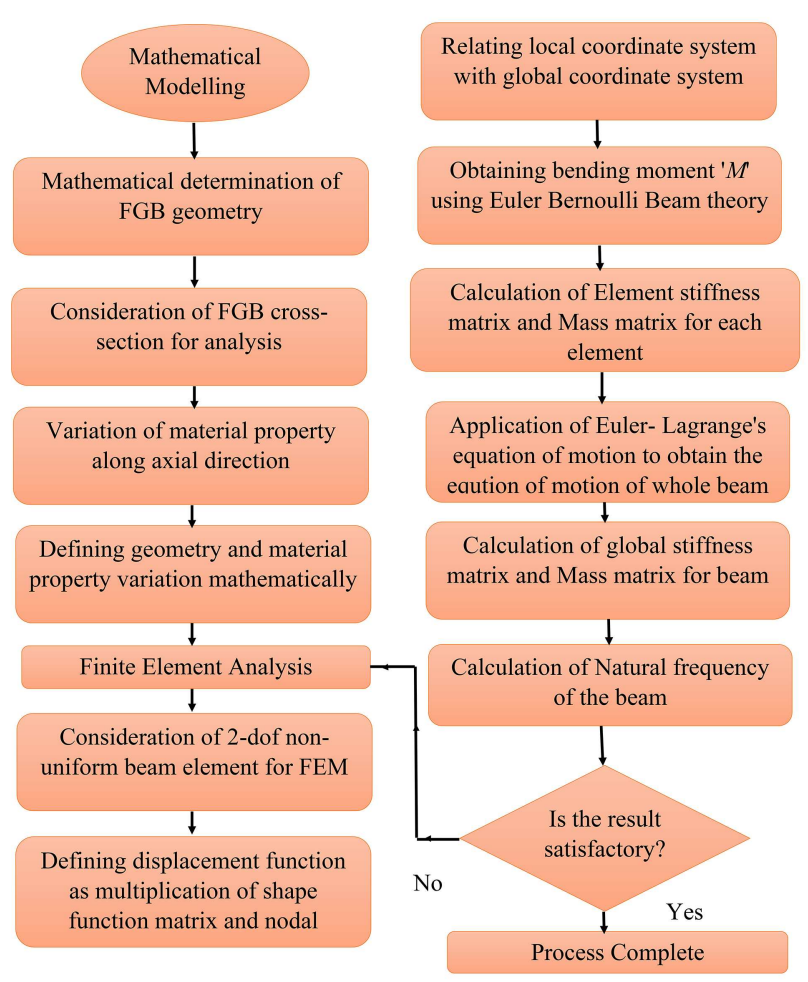

Figure 5. Flowchart of the steps involved in mathematical modeling and finite element analysis.

Details of the steps involved in the mathematical modeling and FEA are presented in Figure 5. In case unsatisfactory results are obtained from the FEA, the process for the natural frequency repeats until reaching the satisfactory results.

\section{Numerical results and discussion}

This section is mainly devoted to the numerical results of the natural frequencies for free transverse vibration of uniform and non-uniform beams under different boundary conditions. Firstly, the results related to uniform and non-uniform beams were obtained. To this end, aluminum $(\mathrm{Al})$ and zirconia $\left(\mathrm{ZrO}_{2}\right)$ were used as the metal and ceramic constituents, respectively, as shown in Table 1 . In the required calculations, $b=0.02, h_{0}=0.001$, and $L=0.2$ were taken into account for the uniform beam from [13] to compare the results from the present method. In the case of nonuniform beam, we have $L=1, b=0.02, h_{0}=0.01$. In

Table 1. Properties of the constituent materials used in [13].

\begin{tabular}{cccc} 
Properties & Unit & Aluminum & Zirconia $\left(\mathbf{Z r O}_{\mathbf{2}}\right)$ \\
\hline$E$ & $\mathrm{GPa}$ & 70 & 200 \\
$\rho$ & $\mathrm{Kg} / \mathrm{m}^{3}$ & 2702 & 5700 \\
\hline
\end{tabular}


this study, $\mathrm{Al}$ and $\mathrm{ZrO}_{2}$ were the materials used at the left most surface (at $x=0$ ) and the right most surface (at $x=L)$, respectively.

To calculate the non-dimensional natural frequency $(\lambda)$, the following formula was used in comparing the obtained result with that obtained by [13] as follows:

$$
\lambda=\omega L^{2} \sqrt{\frac{\rho_{L} A_{L}}{E_{L} I_{L}}},
$$

where $\omega$ is the angular natural frequency and depends on the mode of vibration $(\mathrm{rad} / \mathrm{s}), \rho_{L}$ the density of the material used at the left most surface of the beam $\left(\mathrm{kg} / \mathrm{m}^{3}\right), A_{L}$ is the area of cross-section of the beam at the left most part of the beam $\left(\mathrm{m}^{2}\right), E_{L}$ Young's modulus of the material present at the left most part of the beam $(\mathrm{Pa}), I_{L}$ the area moment of inertia at the left most part of the beam $\left(\mathrm{m}^{4}\right)$, and $L$ the length of the beam $(\mathrm{m})$.

Followed by considering all the similar conditions discussed in [13], the results of the present method were found to be in good agreement with similar results, as shown in Table 2. Present results were found to be well in agreement in-between the ADM and the FEM of [13], as their values were found to be slightly higher than the FEM results and slightly below the ADM results. The mass of uniform beam in both exponential and power laws with the same dimensions was compared, and $\alpha=3$ yielded the same amount of mass in the exponential grading as that of power law grading when $n=2.5$. According to Table 3 , the uniform beams of the same mass in both exponential

Table 2. Comparison of non-dimensional fundamental frequencies $(\lambda)$ of uniform AFG $\left(\mathrm{Al}-\mathrm{ZrO}_{2}\right)$ beam in different boundary conditions for $\alpha=3$.

\begin{tabular}{clcccc}
\hline Boundary condition & Method used & Mode 1 & Mode 2 & Mode 3 & Mode 4 \\
\hline \multirow{2}{*}{ C-F } & Present & 2.854463 & 21.4957915 & 63.68948972 & 126.7057 \\
& Ref. [13] & 2.863 & 21.394 & 63.712 & 127.21 \\
& FEM [13] & 2.852 & 21.494 & 63.673 & 126.575 \\
& & & & & \\
& Present & 10.36696 & 41.9729437 & 94.5556821 & 168.2817 \\
H-H & Ref. [13] & 10.5 & 42.376 & 95.525 & 169.937 \\
& FEM [13] & 10.368 & 41.973 & 94.51 & 167.997 \\
& & & & & \\
& Present & 15.71721 & 52.8117755 & 110.689377 & 189.7663 \\
& Ref. [13] & 15.952 & 53.417 & 111.903 & 191.646 \\
& FEM [13] & 15.718 & 52.807 & 110.611 & 189.356 \\
& & & & & \\
& Present & 24.93755 & 67.1232031 & 130.3613409 & 214.8374 \\
& Ref. [13] & 25.625 & 688.537 & 132.592 & 217.742 \\
& FEM [13] & 24.942 & 67.113 & 130.236 & 214.258 \\
\hline
\end{tabular}

Table 3. Comparison of non-dimensional fundamental frequencies of uniform AFG $\left(\mathrm{Al}-\mathrm{ZrO}_{2}\right)$ beam for power law and exponential law of gradation in different boundary conditions for $\alpha=3$ and $n=2.5$.

\begin{tabular}{clcccc}
\hline Boundary conditions & Gradation scheme & Mode 1 & Mode 2 & Mode 3 & Mode 4 \\
\hline \multirow{2}{*}{ C-F } & Power law [21] & 2.788372 & 21.46919 & 63.90569 & 126.9603 \\
& Exponential law [13] & 2.854463 & 21.49579 & 63.68949 & 126.7057 \\
& & & & & \\
H-H & Power law [21] & 10.32393 & 41.95427 & 94.46947 & 168.0887 \\
& Exponential law [13] & 10.36696 & 41.97294 & 94.55568 & 168.2817 \\
& & & & & \\
C-H & Power law [21] & 15.68958 & 52.92778 & 110.7761 & 189.7579 \\
& Exponential law [13] & 15.71721 & 52.81178 & 110.6894 & 189.7663 \\
& & & & & \\
C-C & Power law [21] & 24.96248 & 67.07427 & 130.1854 & 214.5121 \\
& Exponential law [13] & 24.93755 & 67.1232 & 130.3613 & 214.8374 \\
\hline
\end{tabular}


law grading and power law grading produced more or less the same natural frequencies under different boundary conditions.

In the case of non-uniform beam, the fundamental frequency was lower than that of the uniform beam, as observed in Table 4. This finding was already expected because the beam with exponentially decreasing thickness had been taken into account. In this situation, given that zirconia with higher stiffness was the mate- rial used at the right most surface of the beam, with a decrease in the thickness, the beam would lose some material, hence a decrease in its mass and stiffness. As a result, this can be referred to as the cause of decrement in the fundamental frequencies. According to Table 5 , there is no considerable difference between the results of power law gradation and exponential law of gradation provided that same mass is considered.

According to Table 1, the numerical outcomes

Table 4. Comparison of non-dimensional fundamental frequencies of AFG $\left(\mathrm{Al}-\mathrm{ZrO}_{2}\right)$ uniform beam vs. non-uniform beam in different boundary conditions for $\alpha=3$ and $\beta=0.1$.

\begin{tabular}{|c|c|c|c|c|c|}
\hline Boundary condition & Method used & Mode 1 & Mode 2 & Mode 3 & Mode 4 \\
\hline \multirow{2}{*}{$\mathrm{C}-\mathrm{F}$} & Present & 2.89199 & 20.8508 & 60.97785 & 120.9449 \\
\hline & Ref. [13] & 2.863 & 21.394 & 63.712 & 127.21 \\
\hline \multirow{2}{*}{$\mathrm{H}-\mathrm{H}$} & Present & 9.894899 & 39.92297 & 89.94498 & 160.0938 \\
\hline & Ref. [13] & 10.5 & 42.376 & 95.525 & 169.937 \\
\hline \multirow{2}{*}{$\mathrm{C}-\mathrm{H}$} & Present & 15.17266 & 50.42204 & 105.4868 & 180.7283 \\
\hline & Ref. [13] & 15.952 & 53.417 & 111.903 & 191.646 \\
\hline \multirow{2}{*}{$\mathrm{C}-\mathrm{C}$} & Present & 23.65832 & 63.78144 & 123.9482 & 204.3266 \\
\hline & Ref. [13] & 25.625 & 68.537 & 132.592 & 217.742 \\
\hline
\end{tabular}

Table 5. Comparison of non-dimensional fundamental frequencies of AFG $\left(\mathrm{Al}-\mathrm{ZrO}_{2}\right)$ non-uniform beam in different boundary conditions for $\alpha=3, n=2.5$, and $\beta=0.1$.

\begin{tabular}{clcccc}
\hline Boundary condition & Gradation type & Mode 1 & Mode 2 & Mode 3 & Mode 4 \\
\hline C-F & Exponential law & 2.89199 & 20.8508 & 60.97785 & 120.9449 \\
& Power law & 2.824893 & 20.8322 & 61.18508 & 121.1914 \\
& & & & & \\
H-H & Exponential law & 9.894899 & 39.92297 & 89.94498 & 160.0938 \\
& Power law & 9.849662 & 39.86223 & 89.78602 & 159.7856 \\
& & & & & \\
C-H & Exponential law & 15.17266 & 50.42204 & 105.4868 & 180.7283 \\
& Power law & 15.14726 & 50.49737 & 105.495 & 180.5936 \\
& & & & & \\
& & & & & \\
C-C & Powponential law & 23.65832 & 63.78144 & 123.9482 & 204.3266 \\
& & 23.68861 & 63.71877 & 123.7262 & 203.9088 \\
\hline
\end{tabular}




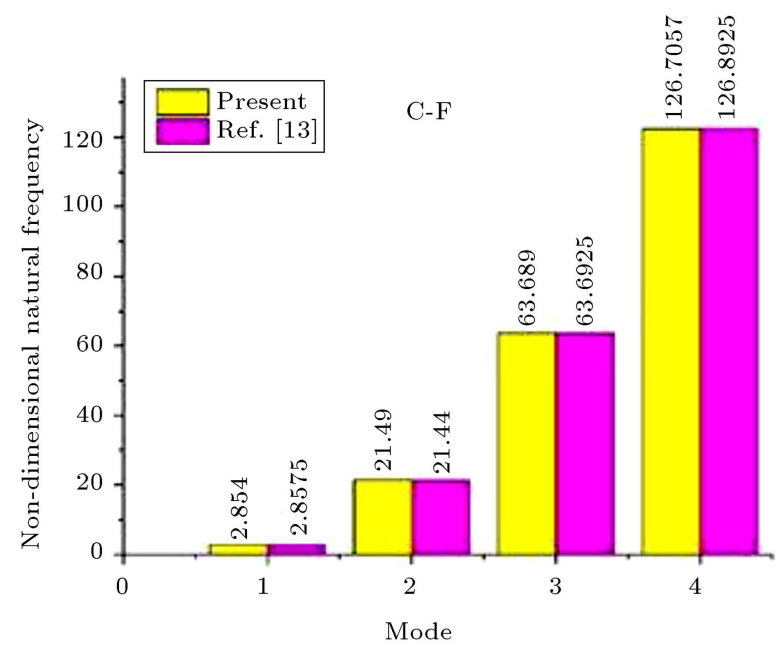

(a)

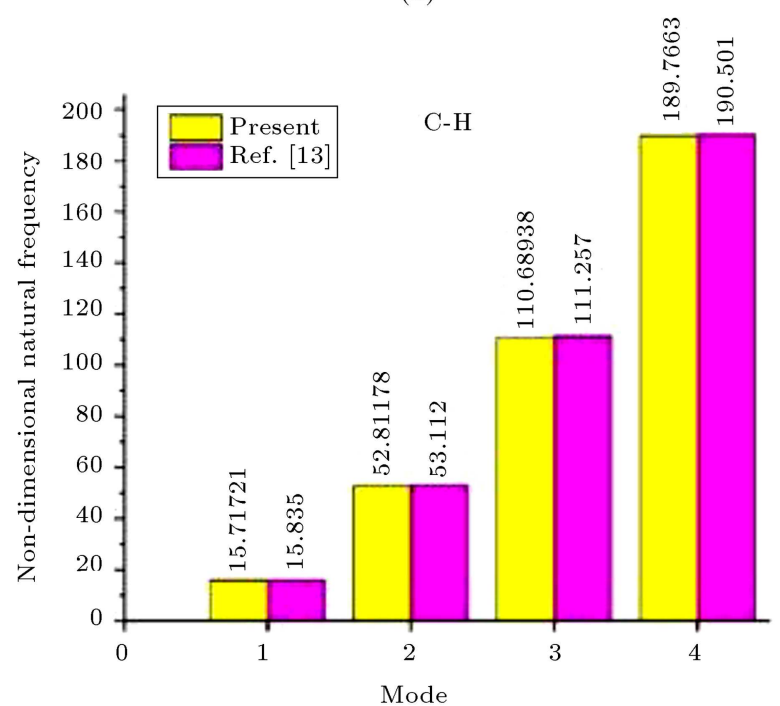

(c)

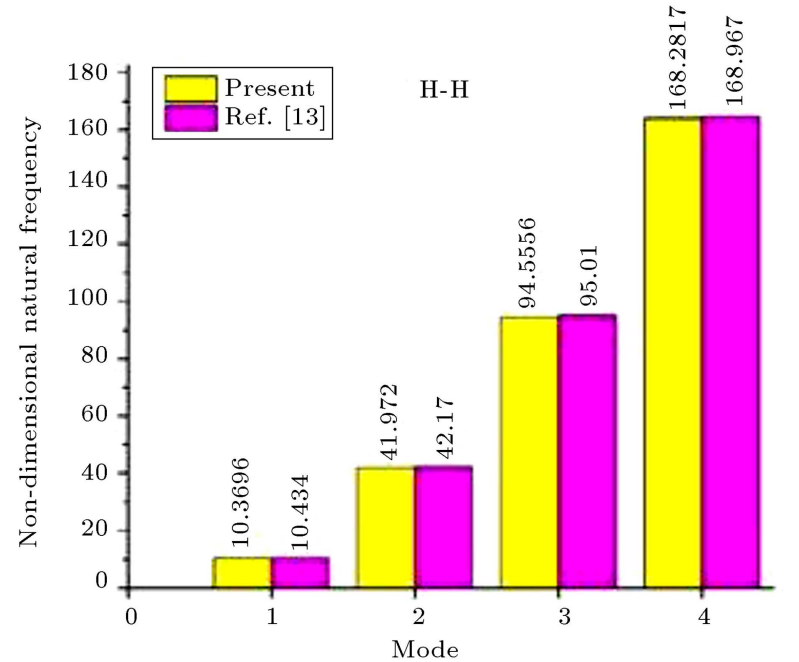

(b)

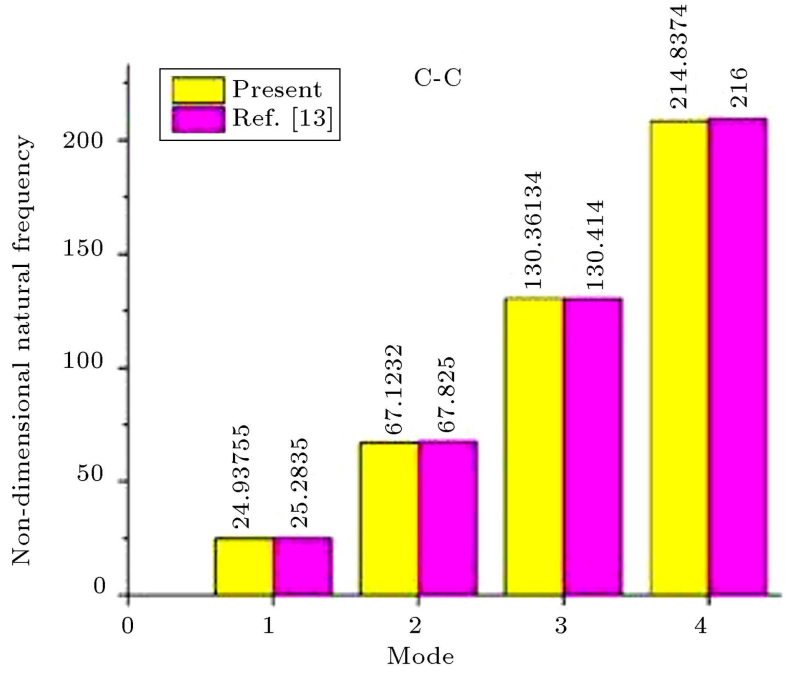

(d)

Figure 6. Comparison of the non-dimensional natural frequencies $(\lambda)$ for different modes of vibration for (a) Clamped-free, (b) hinged-hinged, (c) clamped-hinged, and (d) clamped-clamped boundary conditions.

of the present method were reasonably convergent to those of ADM and software package-based FEM in [13]. To better understand the mentioned convergence, a graphical comparison between the results of the current method and average of ADM and FEM results of [13] was simultaneously made, the outcome of which is presented in Figure 6 for each boundary condition. Figure 7 depicts the Absolute Mean Deviation (AMD) for different boundary conditions, derived from the suggested average value result of [13].

Tables 6-9 elaborate the effects of geometry and gradation parameters on the fundamental frequency of non-uniform beam under different boundary conditions. As clearly observed in Tables 6 and 7, with an increase in the geometry parameter, the nondimensional frequencies would decrease. Figure 8 also illustrates a graphical representation of monotonously decreasing characteristics of fundamental frequencies

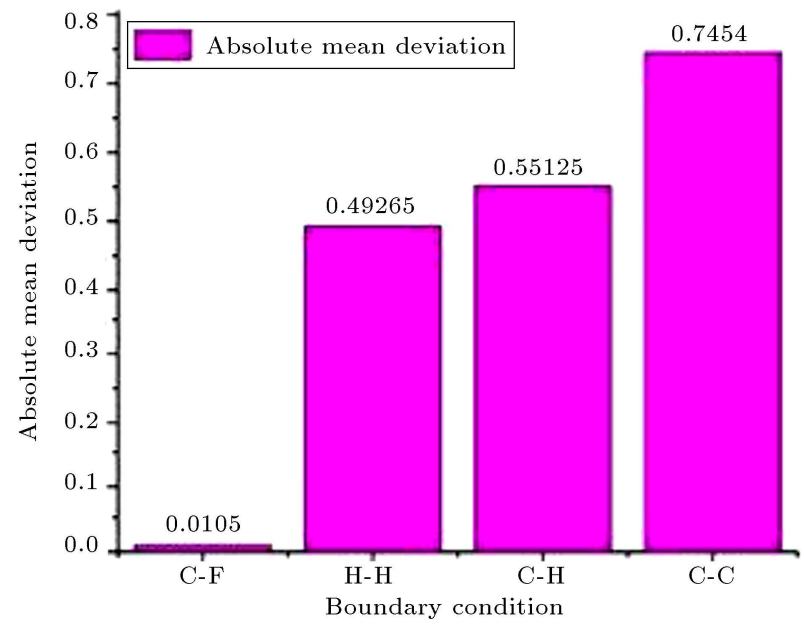

Figure 7. Absolute mean deviation percentage of non-dimensional natural frequency $(\lambda)$ from [13] under respective different boundary conditions. 
Table 6. Variation of the non-dimensional fundamental frequencies of AFG $\left(\mathrm{Al}-\mathrm{ZrO}_{2}\right)$ non-uniform beam with respect to changes in the geometry parameter $(\beta)$ with power law grading $(n=2.5)$ under different boundary conditions.

\begin{tabular}{|c|c|c|c|c|c|c|c|}
\hline \multirow{2}{*}{ Boundary condition } & \multirow{2}{*}{ Mode } & \multicolumn{6}{|c|}{ Exponential geometry parameter $(\boldsymbol{\beta})$} \\
\hline & & 0.1 & 0.2 & 0.4 & 0.6 & 0.8 & 1 \\
\hline \multirow{5}{*}{$\mathrm{C}-\mathrm{F}$} & 1 & 2.8 & 2.9 & 2.9 & 3 & 3 & 3 \\
\hline & 2 & 20.8 & 20.2 & 19 & 17.8 & 16.6 & 15.6 \\
\hline & 3 & 61.2 & 58.6 & 53.6 & 49 & 44.8 & 40.9 \\
\hline & 4 & 121.2 & 115.6 & 105.2 & 95.6 & 86.8 & 78.7 \\
\hline & 5 & 201.4 & 192 & 174.2 & 157.9 & 142.9 & 129.2 \\
\hline \multirow{5}{*}{ H-H } & 1 & 9.9 & 9.4 & 8.5 & 7.7 & 6.9 & 6.2 \\
\hline & 2 & 40 & 38 & 34.3 & 30.9 & 27.9 & 25.1 \\
\hline & 3 & 90.5 & 86.1 & 77.7 & 70.2 & 63.3 & 57 \\
\hline & 4 & 163.1 & 155 & 140.2 & 126.9 & 115 & 104.1 \\
\hline & 5 & 276.7 & 263.4 & 237.7 & 213.1 & 190.1 & 169.1 \\
\hline \multirow{5}{*}{$\mathrm{C}-\mathrm{H}$} & 1 & 15.2 & 14.6 & 13.6 & 12.652 & 11.7531 & 10.9143 \\
\hline & 2 & 50.7 & 48.3 & 44 & 40.1055 & 36.5207 & 33.2545 \\
\hline & 3 & 106.6 & 101.6 & 92.2 & 83.6131 & 75.8374 & 68.7797 \\
\hline & 4 & 184.2 & 175.6 & 159.9 & 145.8132 & 133.019 & 121.1962 \\
\hline & 5 & 308.6 & 292.1 & 261 & 232.6496 & 207.2354 & 184.8249 \\
\hline \multirow{5}{*}{$\mathrm{C}-\mathrm{C}$} & 1 & 23.7 & 22.5 & 20.3 & 18.3 & 16.6 & 15.1 \\
\hline & 2 & 63.8 & 60.6 & 54.7 & 49.4 & 44.7 & 40.4 \\
\hline & 3 & 124.2 & 118 & 106.6 & 96.3 & 86.9 & 78.5 \\
\hline & 4 & 205.6 & 195.5 & 176.6 & 159.5 & 144 & 129.8 \\
\hline & 5 & 309.3 & 294.2 & 265.9 & 240 & 216.5 & 195.4 \\
\hline
\end{tabular}

Table 7. Variation of non-dimensional fundamental frequencies of AFG $\left(\mathrm{Al}-\mathrm{ZrO}_{2}\right)$ non-uniform beam with respect to change in geometry parameter $(\beta)$ with exponential law of grading $(\alpha=3)$ under different boundary conditions.

\begin{tabular}{|c|c|c|c|c|c|c|c|}
\hline \multirow{2}{*}{ Boundary condition } & \multirow{2}{*}{ Mode } & \multicolumn{6}{|c|}{ Exponential geometry parameter $(\beta)$} \\
\hline & & 0.1 & 0.2 & 0.4 & 0.6 & 0.8 & 1 \\
\hline \multirow{5}{*}{$\mathrm{C}-\mathrm{F}$} & 1 & 2.9 & 2.9 & 3 & 3 & 3.0723 & 3.0909 \\
\hline & 2 & 20.9 & 20.2 & 19 & 17.8 & 16.6391 & 15.5417 \\
\hline & 3 & 61.2 & 58.6 & 53.6 & 49 & 44.8122 & 40.9153 \\
\hline & 4 & 122.4 & 116.7 & 106.1 & 96.3 & 87.35 & 79.1836 \\
\hline & 5 & 203.8 & 193.9 & 176.1 & 160.4 & 146.4825 & 133.9566 \\
\hline \multirow{5}{*}{$\mathrm{H}-\mathrm{H}$} & 1 & 9.9 & 9.4 & 8.5 & 7.7 & 6.9 & 6.1 \\
\hline & 2 & 40 & 38 & 34.3 & 31 & 27.9 & 25.2 \\
\hline & 3 & 90.6 & 86.1 & 77.8 & 70.3 & 63.4 & 57.1 \\
\hline & 4 & 163.2 & 155.2 & 140.4 & 127.2 & 115.2 & 104.4 \\
\hline & 5 & 277.1 & 263.8 & 237.9 & 213.2 & 190.2 & 169.2 \\
\hline \multirow{5}{*}{ C-H } & 1 & 15.2 & 14.6 & 13.6 & 12.6668 & 11.7702 & 10.9362 \\
\hline & 2 & 50.5 & 48.3 & 44 & 40.0451 & 36.4733 & 33.2177 \\
\hline & 3 & 106.5 & 101.5 & 92.1 & 83.5308 & 75.7661 & 68.7225 \\
\hline & 4 & 184.3 & 175.8 & 160.1 & 145.9887 & 133.1571 & 121.2849 \\
\hline & 5 & 308.8 & 292.2 & 261 & 232.6166 & 207.2262 & 184.8701 \\
\hline \multirow{5}{*}{$\mathrm{C}-\mathrm{C}$} & 1 & 23.7 & 22.5 & 20.3 & 18.3 & 16.6 & 15.1 \\
\hline & 2 & 63.8 & 60.7 & 54.8 & 49.5 & 44.7 & 40.4 \\
\hline & 3 & 124.3 & 118.2 & 106.8 & 96.4 & 87 & 78.5 \\
\hline & 4 & 205.9 & 195.7 & 176.9 & 159.7 & 144.1 & 129.9 \\
\hline & 5 & 309.8 & 294.6 & 266.1 & 240.1 & 216.6 & 195.5 \\
\hline
\end{tabular}


Table 8. Variation of non-dimensional fundamental frequencies of AFG (Al- $\left.\mathrm{ZrO}_{2}\right)$ non-uniform beam $(\beta=0.1)$ with respect to power law exponent $(n)$ under different boundary conditions.

\begin{tabular}{|c|c|c|c|c|c|c|c|c|}
\hline \multirow{2}{*}{ Boundary condition } & \multirow{2}{*}{ Mode } & \multicolumn{7}{|c|}{ Power law exponent $(n)$} \\
\hline & & 0.1 & 0.2 & 0.5 & 1 & 2 & 5 & 10 \\
\hline \multirow{5}{*}{$\mathrm{C}-\mathrm{F}$} & 1 & 3.9 & 3.7 & 3.3 & 3 & 2.9 & 2.9 & 3.1 \\
\hline & 2 & 24.2 & 23.6 & 22.5 & 21.7 & 21 & 20.3 & 20 \\
\hline & 3 & 67.8 & 66.9 & 65 & 63.6 & 62 & 59.2 & 57.6 \\
\hline & 4 & 134 & 132.6 & 129.8 & 127.1 & 123.8 & 118.8 & 115.5 \\
\hline & 5 & 222.9 & 221.2 & 217.2 & 212.5 & 206.1 & 197.5 & 192.9 \\
\hline \multirow{5}{*}{$\mathrm{H}-\mathrm{H}$} & 1 & 10.9 & 10.8 & 10.6 & 10.4 & 10 & 9.6 & 9.4 \\
\hline & 2 & 43.5 & 43.3 & 42.6 & 41.6 & 40.4 & 38.8 & 38.1 \\
\hline & 3 & 98.5 & 98 & 96.3 & 94.1 & 91.3 & 88.2 & 86.5 \\
\hline & 4 & 177.8 & 176.7 & 173.8 & 169.9 & 164.7 & 158.7 & 155.9 \\
\hline & 5 & 300.9 & 298.8 & 293.5 & 287.1 & 279.2 & 270.2 & 265.9 \\
\hline \multirow{5}{*}{$\mathrm{C}-\mathrm{H}$} & 1 & 16.8 & 16.4 & 15.7 & 15.3 & 15.2 & 15 & 14.9 \\
\hline & 2 & 54.6 & 53.9 & 52.4 & 51.6 & 50.9 & 49.4 & 48.4 \\
\hline & 3 & 114.7 & 113.4 & 111 & 109 & 106.9 & 103.6 & 101.6 \\
\hline & 4 & 198.2 & 196.4 & 192.6 & 188.9 & 184.4 & 178.6 & 175.2 \\
\hline & 5 & 307.5 & 305 & 299.4 & 292.8 & 284.2 & 274.6 & 270.6 \\
\hline \multirow{5}{*}{$\mathrm{C}-\mathrm{C}$} & 1 & 24.3 & 23.9 & 23.2 & 23.1 & 23.5 & 23.9 & 23.6 \\
\hline & 2 & 67.3 & 66.5 & 65 & 64.3 & 63.9 & 63.4 & 63.1 \\
\hline & 3 & 132.7 & 131.3 & 128.8 & 126.8 & 124.8 & 122.5 & 121.9 \\
\hline & 4 & 221.1 & 219.1 & 215.1 & 211.3 & 207 & 202.1 & 200.7 \\
\hline & 5 & 334 & 331.4 & 325.5 & 319.2 & 311.6 & 303.8 & 300.6 \\
\hline
\end{tabular}

Table 9. Variation of non-dimensional fundamental frequencies of AFG $\left(\mathrm{Al}-\mathrm{ZrO}_{2}\right)$ non-uniform beam $(\beta=0.1)$ with respect to exponential law parameter $(\alpha)$ in different boundary conditions.

\begin{tabular}{|c|c|c|c|c|c|c|c|c|}
\hline \multirow{2}{*}{ Boundary condition } & \multirow{2}{*}{ Mode } & \multicolumn{7}{|c|}{ Exponential law parameter $(\alpha)$} \\
\hline & & -10 & -5 & -3 & $\mathbf{0}$ & 3 & 5 & 10 \\
\hline \multirow{5}{*}{$\mathrm{C}-\mathrm{F}$} & 1 & 3.6 & 3.3 & 3.2 & 3 & 2.9 & 2.9 & 3.1 \\
\hline & 2 & 23.1 & 22.7 & 22.4 & 21.7 & 20.9 & 20.5 & 20.1 \\
\hline & 3 & 65.9 & 65.4 & 65 & 63.6 & 61.2 & 59.8 & 57.9 \\
\hline & 4 & 131.8 & 130.9 & 130.1 & 127.1 & 122.4 & 119.7 & 116 \\
\hline & 5 & 221.3 & 220.1 & 218.4 & 212.5 & 203.8 & 199.2 & 193.5 \\
\hline \multirow{5}{*}{$\mathrm{H}-\mathrm{H}$} & 1 & 10.9 & 10.8 & 10.7 & 10.4 & 9.9 & 9.7 & 9.5 \\
\hline & 2 & 43.5 & 43.1 & 42.7 & 41.6 & 40 & 39.2 & 38.2 \\
\hline & 3 & 98.4 & 97.6 & 96.7 & 94.1 & 90.6 & 88.9 & 86.8 \\
\hline & 4 & 177.4 & 176.1 & 174.6 & 169.9 & 163.2 & 160 & 156.4 \\
\hline & 5 & 298.7 & 296.5 & 294.3 & 287.1 & 277.1 & 272.2 & 266.7 \\
\hline \multirow{5}{*}{$\mathrm{C}-\mathrm{H}$} & 1 & 15.9 & 15.6 & 15.5 & 15.3 & 15.2 & 15.1 & 15 \\
\hline & 2 & 52.9 & 52.5 & 52.2 & 51.6 & 50.5 & 49.8 & 48.7 \\
\hline & 3 & 113 & 112.3 & 111.7 & 109.7 & 106.5 & 104.7 & 102.3 \\
\hline & 4 & 198.9 & 197.6 & 196.1 & 191.2 & 184.3 & 181 & 177.4 \\
\hline & 5 & 331.3 & 329.9 & 327.9 & 320.3 & 308.8 & 302.8 & 295.6 \\
\hline \multirow{5}{*}{$\mathrm{C}-\mathrm{C}$} & 1 & 22.9 & 22.7 & 22.7 & 23.1 & 23.7 & 23.8 & 23.6 \\
\hline & 2 & 65 & 64.6 & 64.5 & 64.3 & 63.8 & 63.5 & 63.1 \\
\hline & 3 & 129.7 & 129 & 128.5 & 126.8 & 124.3 & 123.1 & 122 \\
\hline & 4 & 217.7 & 216.5 & 215.2 & 211.3 & 205.9 & 203.3 & 201 \\
\hline & 5 & 330.8 & 328.6 & 326.3 & 319.2 & 309.8 & 305.6 & 301.2 \\
\hline
\end{tabular}




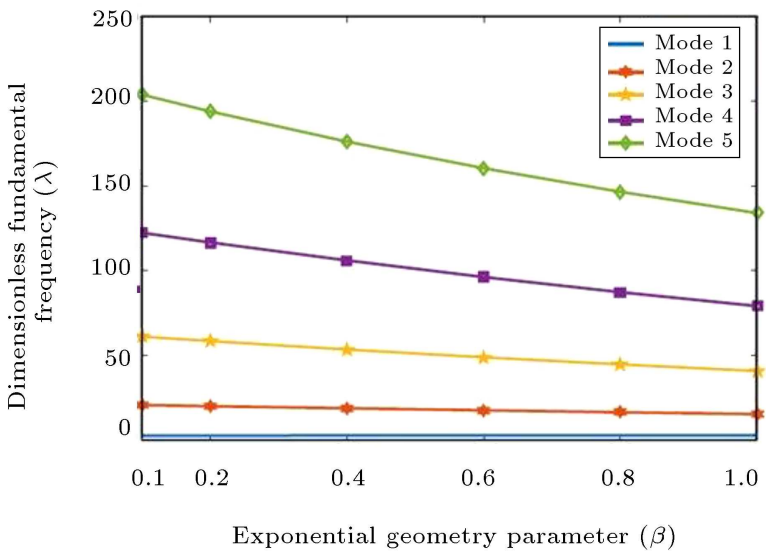

(a)

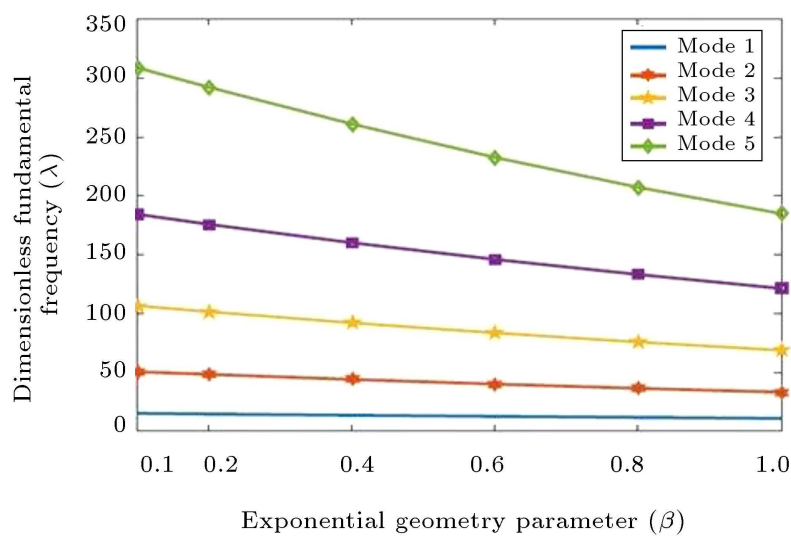

(c)

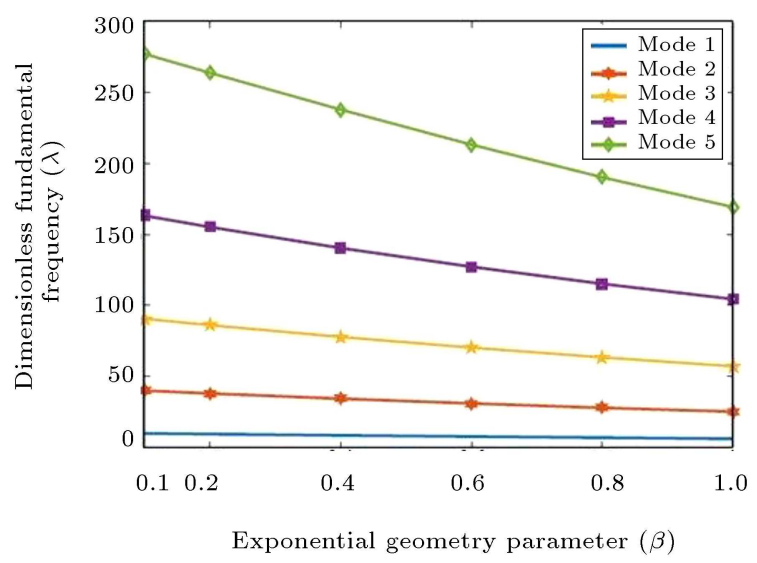

(b)

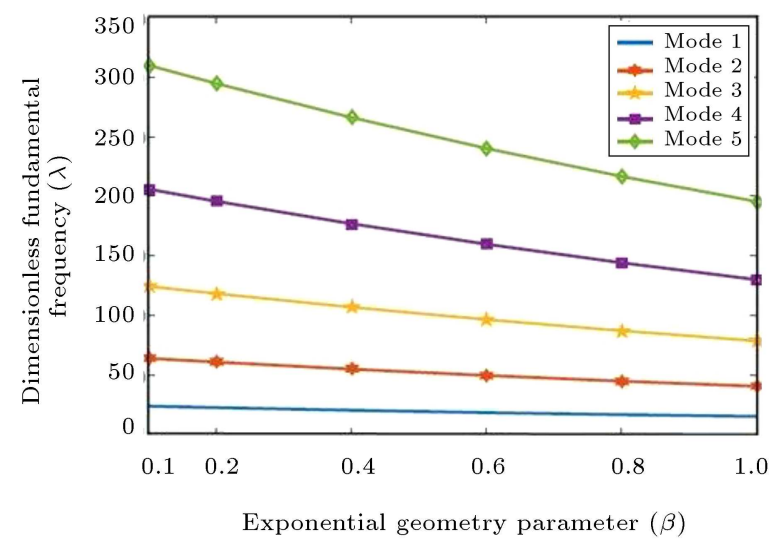

(d)

Figure 8. Effect of geometric non-uniformity parameter $\beta$ on the fundamental frequencies of the AFG beam considering $n=2.5$ in different boundary conditions: (a) Clamped-free boundary condition, (b) hinged-hinged boundary condition, (c) clamped-hinged boundary condition, and (d) clamped-clamped boundary condition at the left and right ends of the AFG non-uniform beam.

with respect to an increase in the geometric parameter $\beta$. Followed by a careful observation of the results with different values of $\beta$, it was concluded that $\beta$ should be less than 0.1 for comparable frequency results with the uniform AFG beam. To evaluate the effect of gradient parameters on the fundamental frequencies, the value $\beta$ was assumed to be 1 . Some unpredictable trends were observed mainly because with an increase in $\beta$, the beam became softer and its mass also decreased; this made it difficult to recognize the trend in a usual manner. As observed in Figures 2 and 3, upon increasing the gradation parameters, the overall material quantity would decrease even if it keeps its dimensions same. This in turn leads to a reduction in the stiffness and mass of the beam. Therefore, it can be naturally expected that these parameters have a direct impact on the fundamental frequencies of the beam. In case of power law grading, the fundamental frequencies followed a decreasing trend continuously up to $n=5$ (Figure 9) and then, they remain constant, implying that further increase in the power law exponent will have no effect on the fundamental frequencies, which is unlike the case of exponential law of grading where the changes mostly occur nearby $\alpha=0$ and remain constant all the time (Figure 10). According to Tables 8 and 9, upon increasing the values of gradation parameters $\alpha$ and $n$, the fundamental frequencies may decrease, with the exception of the 1st mode under clamped-free and clamped-clamped boundary conditions. Although an increase in the constraint results in higher fundamental frequencies, the trend is of non-decreasing nature under these two boundary conditions.

\section{Conclusion}

The present study aimed to analyze a generalized finite element approach based on Euler-Bernoulli beam theory to solve free vibration problems of beams with non-uniform thickness and inhomogeneous material distribution along its axis. The proposed approach is, in fact, a generalized one because it can solve 


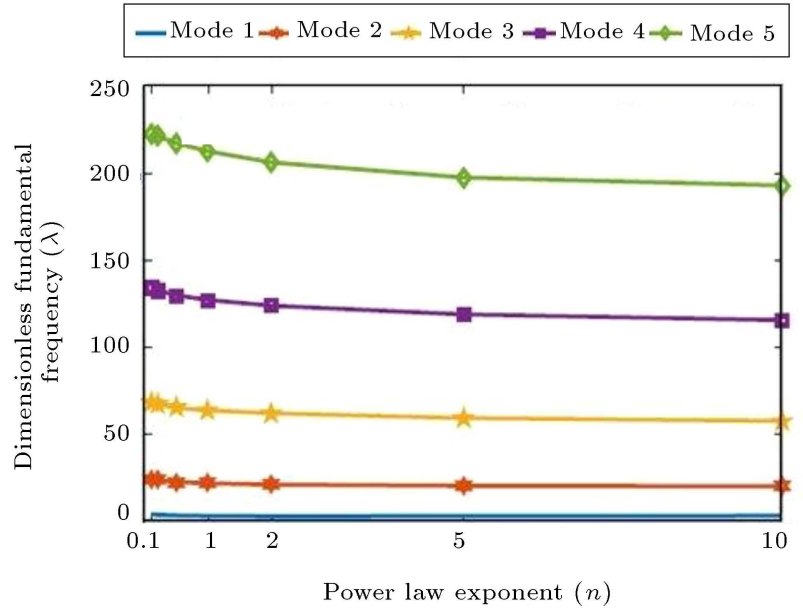

(a)

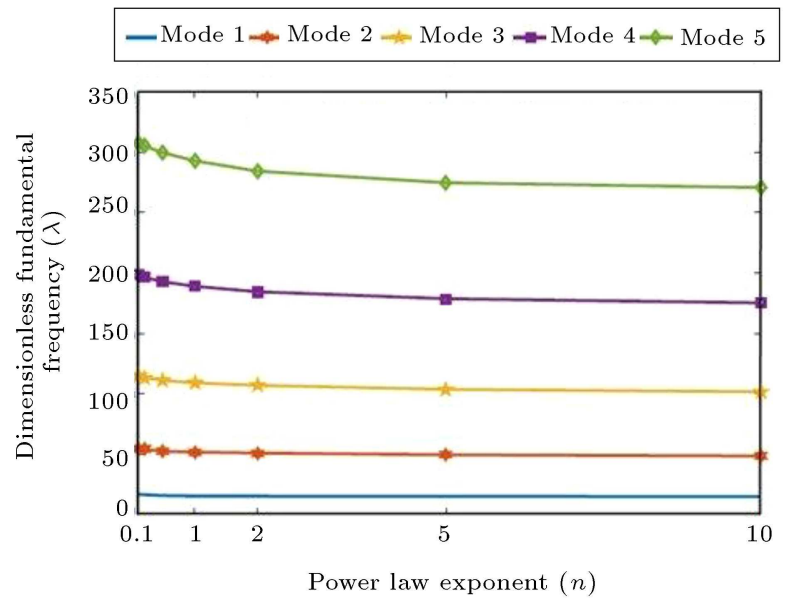

(c)

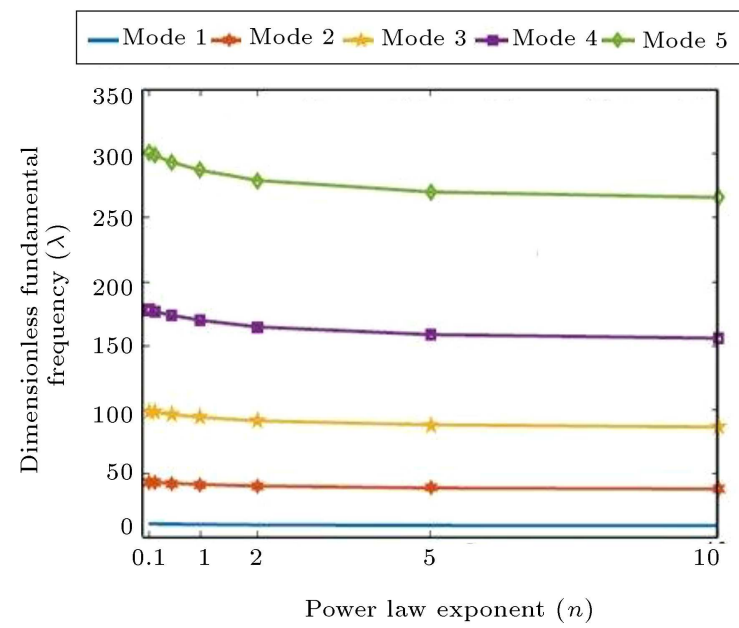

(b)

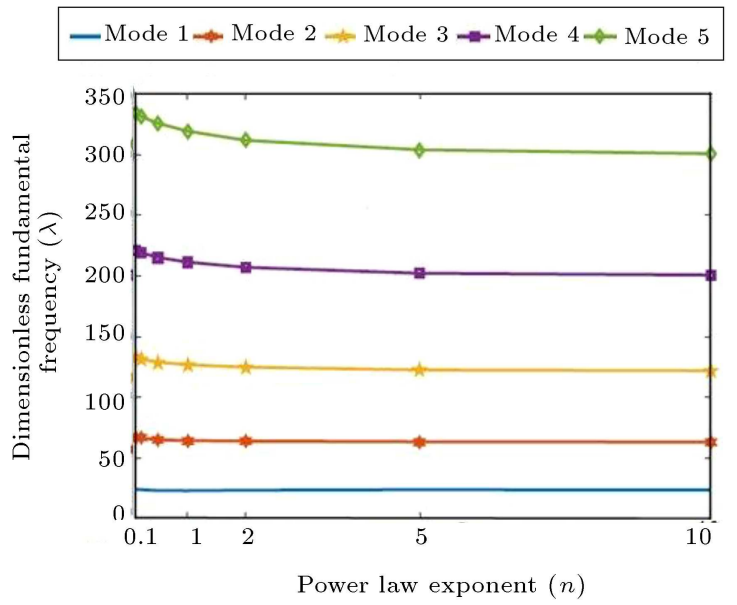

(d)

Figure 9. Effect of power law exponent $n$ on the fundamental frequencies of the AFG beam in different boundary conditions: (a) Clamped-free boundary condition, (b) hinged-hinged boundary condition, (c) clamped-hinged boundary condition, and (d) clamped-clamped boundary condition at the left and right ends of the AFG non-uniform beam, respectively.

free vibration problems of beams with different types of non-uniformities in thickness and inhomogeneity in the material distribution, with only requirement of being a function of axial distance from the origin. In order to validate the effectiveness of the proposed approach, the fundamental frequencies were compared with those of uniform inhomogeneous beams in the analysis done by Cao et al. [13] who assumed the geometry parameter as 0 for the non-uniform beam model under the respective boundary conditions. After finding a decent level of conformation, the present method was employed to evaluate the effect of variations in exponential geometric parameter on the fundamental frequencies of the non-uniform Axially Functionally Graded (AFG) beam. It was found that the fundamental frequency results depended directly on the geometric non-uniformity parameter. Following a careful review the impact of variations in material gradient parameters on the numerical outcomes of the analysis, the following concluding remarks were made:

- Upon increasing the material gradient parameters, the fundamental frequencies in each mode decreased under different boundary conditions. This happened mainly because with an increase in these parameters, the dominance of aluminum would increase in the volume fraction over zirconia, thus making the system more flexible. In addition, the lower values of overall stiffness would result in lower fundamental frequency. Both the gradation schemes yielded almost equal results when considered in the equal masses;

- As expected, an increase in the boundary constraints led to an increase in the values of fundamental frequencies because the initial modes of less constrained systems were suppressed upon increasing 


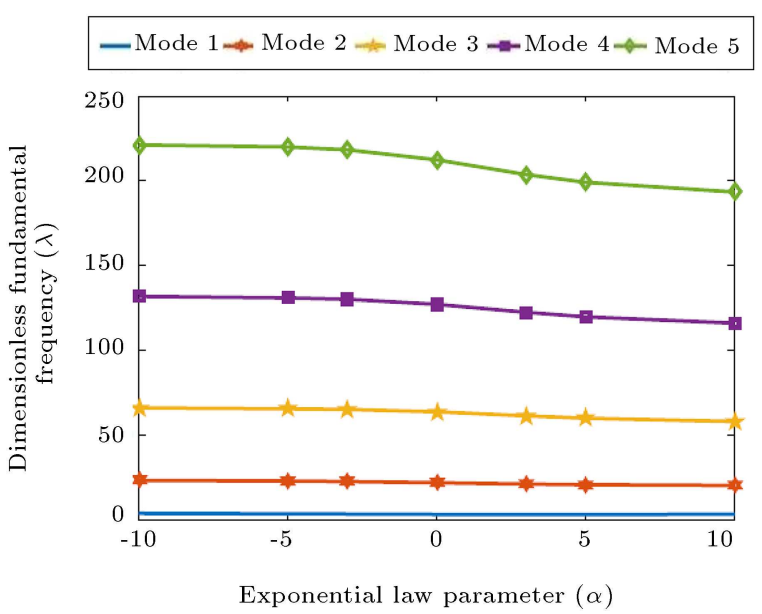

(a)

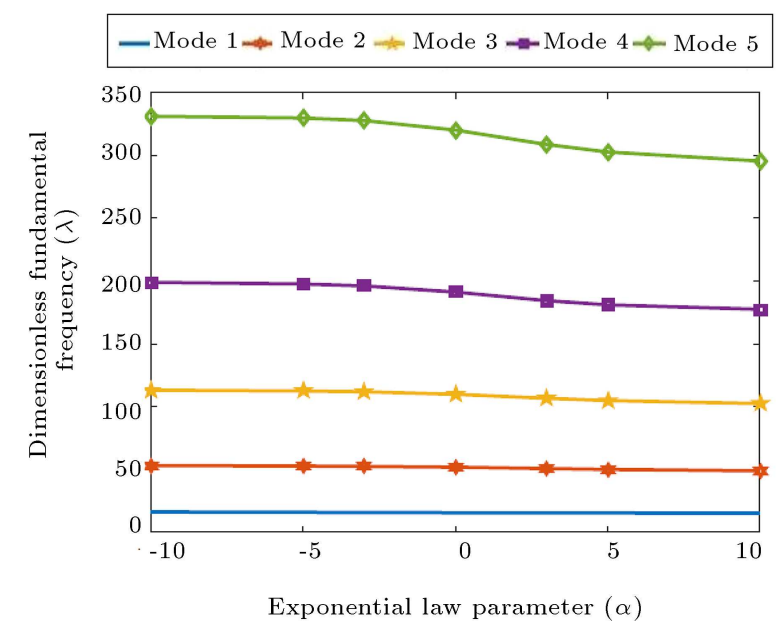

(c)

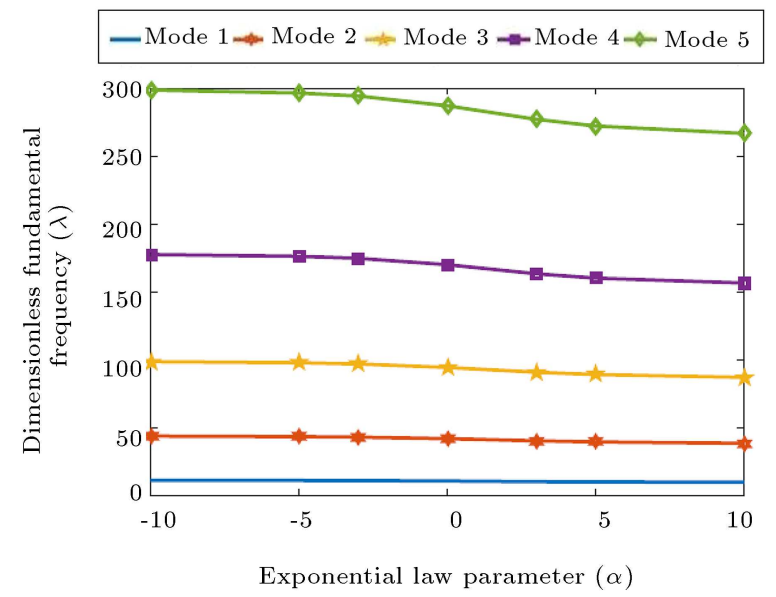

(b)

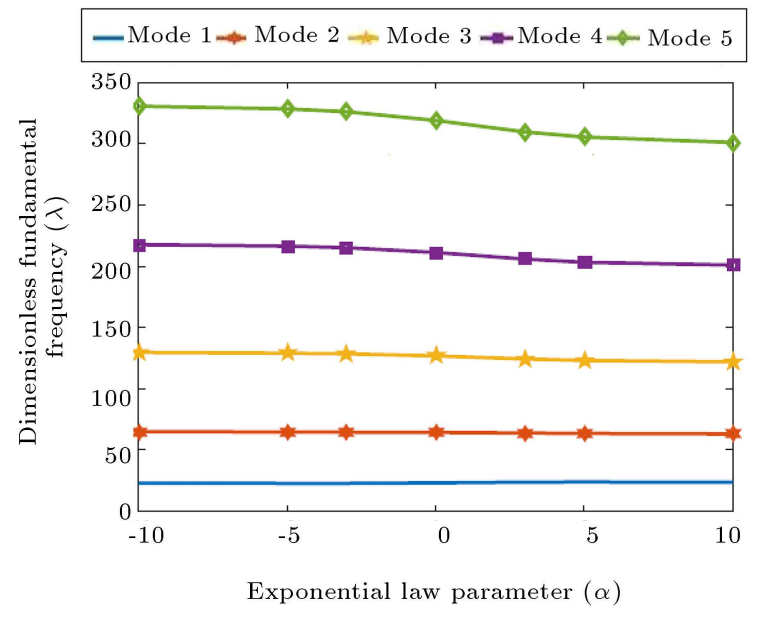

(d)

Figure 10. Effect of the exponential law parameter $\alpha$ on the fundamental frequencies of the AFG beam in different boundary conditions: (a) Clamped-free boundary condition, (b) hinged-hinged boundary condition, (c) clamped- hinged boundary condition, and (d) clamped-clamped boundary condition at the left and right ends of the AFG non-uniform beam.

the constraints. Therefore, in order to vibrate naturally, a higher value of frequency would be required even if the system was to vibrate in the first mode.

\section{Nomenclature}

$L \quad$ Axial length of the beam

$b \quad$ Width of the beam

$x \quad$ Axial distance from the origin

$g(x) \quad$ Exponentially variable thickness function

$h_{0} \quad$ Thickness of the beam at the origin

$\beta \quad$ Exponential geometry parameter

$E(x) \quad$ Young's modulus function

$\rho(x) \quad$ Mass density function
$A(x) \quad$ Cross-sectional area function

$I(x) \quad$ Area moment of inertia function

$P(x) \quad$ Effective material property function

$P_{L} \quad$ Effective material property at the left end of the beam

$P_{R} \quad$ Effective material property at the right end of the beam

$V_{L} \quad$ Volume fraction at the left end of the beam

$V_{R} \quad$ Volume fraction at the right end of the beam

Exponential law parameter

Power law exponent

Transverse displacement function

Local co-ordinate for an element

Span of an element 
$M \quad$ Bending moment

$U \quad$ Strain energy of the beam element

$T \quad$ Kinetic energy of the beam element

$L_{g} \quad$ Lagrangian function

$\omega \quad$ Fundamental angular frequency of the beam element

$\lambda \quad$ Non-dimensional natural frequency of the beam

$E \quad$ Young's modulus of the material

$\rho \quad$ Mass density of the material

C-F Clamped-Free boundary condition

$\mathrm{H}-\mathrm{H} \quad$ Hinged-Hinged boundary condition

C-H Clamped-Hinged boundary condition

C-C Clamped-Clamped boundary condition

\section{References}

1. Koizumi, M. "FGM activities in Japan", Composites Part B: Engineering, 28(1), pp. 1-4 (1997).

2. Sobzak, J. and Drenchev, L. "Metal based functionally graded materials - engineering and modelling", Bentham Science Publisher Ltd. pp. 1-24 (2009).

3. Kapuria, M., Bhattacharya, M., and Kumar, A.N. "Bending and free vibration response of layered functionally graded beams: A theoretical model and its experimental validation", Composite Structures, 82(3), pp. 390-402 (2008).

4. Yang, J. and Chen, Y. "Free vibration and buckling analysis of functionally graded beams with edge cracks", Composite Structures, 83(1), pp. 48-60 (2008).

5. Alshorbagy, A.E., Eltaher, M.A., and Mahmoud, F.F. "Free vibration characteristics of functionally graded beam by finite element method", Applied Mathematical Modelling, 35(1), pp. 412-425 (2011).

6. Simsek, M. and Kocaturk, T. "Free and forced vibration of functionally graded beam subjected to a concentrated moving harmonic load", Composite Structures, 90, pp. 465-473 (2009).

7. Pradhan, K.K. and Chakraverty, S. "Free vibration of Euler and Timoshenko functionally graded beams by Rayleigh-Ritz method", Composites: Part B, 51, pp. 175-184 (2013).

8. Rao, R.S. and Ganesan, N. "Dynamic response of non-uniform composite beams", Journal of Sound and Vibration, 200(5), pp. 563-577 (1997).

9. Karami, G., Malekzadeh, P., and Shahpari, S.A. "A DQEM for vibration of shear deformable non-uniform beams with general boundary conditions", Engineering Structures, 25, pp. 1169-1179 (2003).

10. Aydogdu, M. and Taskin, V. "Free vibration analysis of functionally graded beams with simply supported edges", Material and Design, 28, pp. 1651-1656 (2007).
11. Nguyen, V.L. and Quoc, T.H. "Bending and free vibration analysis of functionally graded plates using new eight unknown shear deformation theory by finite element method", International Journal of Advanced Structural Engineering, 8, pp. 391-399 (2016).

12. Huang, Y. and Li, X.F. "A new approach for free vibration of axially graded beams with non-uniform cross-section", Journal of Sound and Vibration, 329, pp. 2291-2303 (2010).

13. Cao, D., Gao, Y., and Zhang, W. "Free vibration of axially functionally graded beams using the asymptotic development method", Engineering Structures, 173, pp. 442-448 (2018).

14. Ghayesh, M.H. "Non-linear vibration analysis of axially functionally graded shear-deformable tapered beams", Applied Mathematical Modelling, 59, pp. 583596 (2018).

15. Huang, Y., Wang, T., Zhao, Y., et al. "Effect of axially functionally graded material on whirling frequencies and critical speeds of spinning Timoshenko beam", Composite Structures, 192, pp. 355-367 (2018).

16. Salinic, S., Obradovic, A., and Tomovic, A. "Free vibration analysis of axially functionally graded tapered, stepped and continuously segmented rods and beams", Composites Part B, 150, pp. 135-143 (2018).

17. Zheng, S., Chen, D., and Wang, H. "Size dependent nonlinear free vibration of axially functionally graded tapered microbeams using finite element method", Thin-Walled Structures, 139, pp. 46-52 (2019).

18. Sahin, S., Karahan, E., Kilic, B., et al. "Finite element method for vibration analysis of Timoshenko beams", 9th International Conference on Recent Advances in Space Technologies (RAST), Istanbul, Turkey, pp. 673-679 (2019).

19. Xie, K., Wang, Y., and Fu, T. "Dynamic response of axially functionally graded beam with longitudinaltransverse coupling effect", Aerospace Science and Technology, 85, pp. 85-95 (2019).

20. Sun, D.L. and Li, X.F. "Initial value method for free vibration of axially loaded functionally graded Timoshenko beams with non-uniform cross-section", Mechanics Based Design of Structures and Machines, 47(1), pp. 102-120 (2019).

21. Hughes, T.J.R., Cottrell, J.A., and Bzileves, Y. "Isogeometric analysis: CAD, finite elements, NURBS, exact geometry and mesh refinement", Computer Methods in Applied Mechanics and Engineering, 194(39-41), pp. 4135-4195 (2005).

22. Nguyen, H.X., Nguyen, T., Wahab, M.A., et al. "A refined quasi-3D isogeometric analysis for functionally graded microplates based on the modified couple stress theory", Computer Methods in Applied Mechanics and Engineering, 313, pp. 904-940 (2017).

23. Thanh, C.L., Ferreira, A.J.M., and Wahab, M.A. "A refined size-dependent couple stress theory for laminated composite micro-plates using isogeometric analysis", Thin-Walled Structures, 145, p. 106427 (2019). 
24. Thanh, C.L., Tran, L.V., Bui, T.Q., et al. "Isogeometric analysis for size-dependent nonlinear thermal stability of porous FG microplates", Composite Structures, 221, p. 110838 (2019).

25. Thanh, C.L., Van, P.P., Thai, C.H., et al. "Isogeometric analysis of functionally graded carbon nanotube reinforced composite nanoplates using modified couple stress theory", Composite Structures, 184(15), pp. 633-649 (2018).

26. Van, P.H., Tran, L.V., Ferreira, A.J.M., et al. "Nonlinear transient isogeometric analysis of smart piezoelectric functionally graded material plates based on generalized shear deformation theory under thermoelectro-mechanical loads", Nonlinear Dynamics, 87, pp. 879-894 (2017).

27. Van, P.P., Thai, C.H., Xuan, H.N., et al. "Porositydependent nonlinear transient responses of functionally graded Nano-plates using iso-geometric analysis", Composites Part B: Engineering, 164, pp. 215-225 (2019).

28. Thanh, C.L., Tran, L.V., Huu, T.V., et al. "The sizedependent thermal bending and buckling analyses of composite laminate microplate based on new modified couple stress theory and isogeometric analysis", Computer Methods in Applied Mechanics and Engineering, 350, pp. 337-361 (2019).

29. Nguyen, T.-T., Nguyen, N.-L., Lee, J., et al. "Analysis of non-uniform polygonal cross-sections for thin-walled functionally graded straight and curved beams", Engineering Structures, 226, p. 111366 (2021).

30. Nguyen, T.-T. and Lee, J. "Interactive geometric interpretation and static analysis of thin-walled bidirectional functionally graded beams", Composite Structures, 191, pp. 1-11 (2018).

31. Nguyen, T.T. and Lee, J. "Flexural-torsional vibration and buckling of thin-walled bi-directional functionally graded beams", Composites Part B, 154, pp. 351-362 (2018).

32. Rajasekaran, S. and Khaniki, H.B. "Finite element static and dynamic analysis of axially functionally graded non-uniform small-scale beams based on nonlocal strain gradient theory", Mechanics of Advanced Materials and Structures, 26(14), pp. 1245-1259 (2019).

33. Voigt, W. "Ueber die beziehung zwischen den beiden elasticitätsconstanten isotroper körper", Annalen der Physik, pp. 573-587 (1889).

\section{Biographies}

Ramya Prakash Sahu is an MTech Scholar in Machine Design and Analysis specialization at the Mechanical Engineering Department of Veer Surendra Sai University of Technology Burla, Odisha, India. He majored in BTech from IGIT Sarang in 2017 and his MTech from Veer Surendra Sai University in 2020.

Mihir Kumar Sutar received his PhD from the Indian Institute of Technology Roorkee in 2015. He is currently working as an Assistant Professor at the Mechanical Engineering Department of Veer Surendra Sai University of Technology Burla, Odisha, India. His research interests include machine design and analysis and robotics.

Sarojrani Pattnaik received her $\mathrm{PhD}$ from Indian Institute of Technology Roorkee in 2014. She is currently working as an Associate Professor at the Mechanical Engineering Department of Veer Surendra Sai University of Technology Burla, Odisha, India. Her research interest includes production engineering. 